\title{
Optimization of Phasor Measurement Unit (PMU) Placement: A Review
}

\author{
Rachana Pandey, H.K. Verma, Arun Parakh, Cheshta Jain Khare
}

\begin{abstract}
In today's world, a Phasor Measurement Unit (PMU) is a crucial component of our power network for managing, controlling, and monitoring. PMU can provide synchronized voltage current, and frequency measurements in real time. We can't put a PMU in every bus in the electrical grid because it's not viable from a productivity and economic standpoint, and it's also not practical for handling huge data. As a result, it's critical to reduce the amount of PMU in the power network while also increasing the power network's observability. The optimal PMU placement problem is solved using a variety of methodologies. The paper's main goal is to provide a brief overview of synchrophasor technology, phasor measurement units (PMU), and optimal PMU placement in order to reduce the number of PMUs in the system while maintaining complete observability and application in today's power systems.
\end{abstract}

Keywords: Wide Area Measurement System(WAMS); Observability; Phasor Measurement Unit(PMU); Supervisory Control And Data Aquisition(SCADA); Global Positioning System(GPS)

\section{INTRODUCTION}

The electric power network is a key piece of infrastructure, and as we all know, the need for electricity in numerous fields is growing by the day. The only way to meet the rising demand is to expand the electricity transmission capacity. Power grid failure can occur as a result of a lack of connected power network infrastructure, a lack of maintenance, and an increase in electricity usage. The electric power business wastes billions of dollars as a result of such losses. Due to the disturbances such as single-phase and three-phase line faults, generator losses, and load variations, the system operating point might diverge from its threshold point. For proper and stable power system functioning, regular monitoring and accurate measurement are required. Measurements from supervisory control and data acquisition(SCADA) are used to estimate the state of the connected power network. SCADA provides unsynchronized

Manuscript received on November 05, 2021.

Revised Manuscript received on November 13, 2021.

Manuscript published on November 30, 2021.

* Correspondence Author

Rachana Pandey*, Department of Electrical Engineering, Shri Govindram Seksaria Institute of Technology and Science Indore (M.P), India. Email: rachanapandey1911@gmail.com

Dr. H.K.Verma, Department of Electrical Engineering, Shri Govindram Seksaria Institute of Technology and Science Indore (M.P), India. Email: vermaharishgs@gmail.com

Dr. Arun Parakh, Department of Electrical Engineering, Shri Govindram Seksaria Institute of Technology and Science Indore (M.P), India. Email: arunparakh.eed@gmail.com

Dr. Cheshta Jain Khare, Department of Electrical Engineering, Shri Govindram Seksaria Institute of Technology and Science Indore (M.P), India. Email: cheshtajain194@gmail.com

(c) The Authors. Published by Blue Eyes Intelligence Engineering and Sciences Publication (BEIESP). This is an open access article under the CC BY-NC-ND license (http://creativecommons.org/licenses/by-nc-nd/4.0/) measurements, which invariably results in erroneous power network estimation. SCADA measurement-does not contain the phase angle of bus voltage or line current. The data test rate is 2-4 samples per cycle, which is relatively low. As a result, the system cannot take measurements very quickly in a dynamic manner.

The problem can be eliminated by using a device known as a Phasor Measurement Unit (PMU). A G Phadke created the first prototype of the PMU in the year 1980 at Virginia Tech. The phasor measuring unit is based on global positioning system(GPS) techniques and is one of the system's essential key elements. It can be used for network monitoring, control, and state estimate. PMU offers accurate and timely system information. PMUs are gating devices that can generate gated phasors, frequencies, and rates of change in voltage frequency estimation.

Nowadays, advanced and accurate measurement devices are required for stable power network operation. In the power network, PMU plays a vital function. It employs Wide Area Measurement System(WAMS) to provide synchronized time tag phasor measurement. Within $1 \mathrm{~ms}$, the GPS in the PMU provides an exact time-stamped synchronized signal. The dependability and stability of the system can be increased by inserting PMU in several areas such as control protection, estimation of system buses, and voltage downfall. This paper provides a brief overview of the PMU, several methods of PMU placement, and previous and ongoing research in the topic of optimal PMU placement in the power network.

\section{STATE OF ART ON OPTIMAL PMU PLACEMENT}

In 2011, Charu Sharma et al present an approach to find optimal number of PMUs by BPSO. Quadratic programming is used for BPSO. They have also given a method for Pseudo Observability for depth-one and depth-two with and without zero injection measurement by BPSO technique. They concluded that BPSO can find the optimal location of PMU, considering conventional measurement and maximizing redundancy. Here they have discussed complete and incomplete observability cases. The results of complete observability are crosschecked by GAMS-IMP solver. For incomplete observability the constraints are so large for GAMS-IMP solver so results for incomplete observability only taken from BPSO method. In 2014, MiniS. Thoma et al, gives a algorithm for finding the optimal number of PMU by performing observability analysis. Now a days for proper observability of the network and for reliable communication between the PMU, optimal PMU location becomes very necessary. The algorithm they proposed place the PMU by doing observability analysis.

Published By:

Blue Eyes Intelligence Engineering and Sciences Publication (BEIESP)

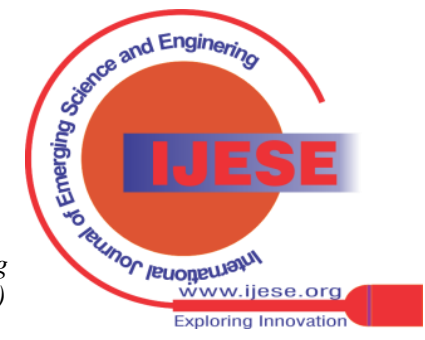


They said that the given algorithm reduces the computational burden because it uses less numerical equation and less number of iteration. They applied the algorithm in power grid Orissa for showing the effectiveness of the method.

In 2014,I.Hemant H. Goklani et al proposed a method for determining minimum number of PMU to make the system observable they use PSAT(Power system analysis toolbox ) and TORA software for determining minimum number of PMUs in the system to make it observable. In their work PSAT software is used for placement of PMU using methods depth First, Graph Theory, simulated Annealing, Re-Spinning Tree and Graph Direct Spanning Tree. And these methods are verified using IEEE 14 Bus system. Also result are compared with the result of Integer Linear Programming(ILP) Method by using TORA software.

In 2015 Tapas kumar maji et al. have used Exponential binary PSO algorithm (EBPSO) for solving the Optimal PMU Placement (OPP) problem for complete observability of the network Alone with normal operating condition various practical contingencies like zero injection bus ,single PMU outage are considered .An adaptive exponentially decay inertia weight coefficient is developed for ensuring multiple solution and for improving the performance and to update the position of the particle in binary form. A sigmoid function is also used with multiple solutions. They have successfully determine the minimum number of PMU.

In 2015,Pronob K. Ghosh et al, has presented a method for OPP for observability of the system and fault observability . In this paper they have created a particular spanning tree from system group model by a procedure .For location of PMU all the cut vertices which are connected to pendent vertex are taken . Some graph terms like cut vertex ,cut edge, pendent vertex are used here for finding the minimum number of PMU installation location for complete observability of the system. Here it is showed that it is very easy to do analysis of a power system by converting it into graph method.

In 2016 Hongyu Wang et al have proposed a method which is based on system topology model and also consider zero injection bus . In the method they have considered different cases of bus connection which includes leaf nodes, buses with more connection branches with same number of connection branches and with two branches. Along with PMU configuration, observable and unobservable bus can be obtained directly by this method, which helps in avoiding large matrix operation and speed up the speed. To reduce the number of PMU the method uses topology of the system and consider zero injection bus .In this method for final PMU placement the degree of link is very important.

In 2017, Somesh Chatterjee et al, investigated the cost effective solution for synchrophasor infrastructure with PMU and dual use lines relay(DULR).They have used Binary Symbiotic Organism Search (BSOS) for OPP and to assure maximum measurement redundancy .They also have extended the BSOS to find the OPP solution .They have showed that investment cost is less if channel limitation of PMU is taken than PMU with infinite channel. For obervability the cost analysis has further extended with DULR's .It is shown that in practical cost perspective the cost for PMU with DULR scheme is found to be lowest.

In 2017, Subrina Sultana Noureen has done analysis on different optimization techniques. They have discussed various algorithms here in short term. The location of the $\mathrm{PMU}$ in each bus is not fissionable from an economical point of view, so it is important to reduce the number of PMU in the bus. Many different type of technique has been introduced from past to present to solve optimal PMU placement (OPP) problem .Many optimization methods has been explained in the paper for solving the OPP problem.

In 2018 , Mohammad Shoaib Shahriar, presents an algorithm for PMU placement in power system. The binary genetic algorithm is used for solving the problem of optimization \& its Aim is to find the optimal set of PMU that is to be installed in Supervisory control and data acquisition (SCADA) measurement based power system. Here it is shown that binary genetic algorithm (BGA) gives a batter performance then the heuristic approach in reaching the global solution. The impact due to presence of bad data in the estimation of performance is least as it ensures the coverage of critical zone by PMU. Here optimal set of both covering and non covering critical zones are shown .this technique of PMU placement is compared with Heuristic approach of PMU.

In 2018 V. Sindhu et al. gives an algorithm to place PMU in power system. PMU has various advantages but place PMU in every point is impossible so to place PMU for full network observability a novel algorithm is used. The number of PMU can be decreased if Zero Injection Bus (ZIB) is used in the system. In this work flower pollination algorithm is used for multi objective optimization optimal PMU placement (OPP) location, by pollination process of flower plant. Numerical algorithms and design has been shown here. It says that the given algorithm is very good and efficient. The redundancy of system increases and reduces the number of PMU installation.

In 2020 Rohit Babu has proposed a methodology which is based on binary integer linear programming method for determining the optimal location of PMU. Here for finding the minimum number of PMUs and their optimal location binary integer linear programming (BILP) programming is used while taking weak buses for observability of the given network. Here for determination of the weak bus in the network weak bus measurement method are used. While taking the weak bus the effect of single PMU outage is also explained. PMU have to be placed in weak bus in the weak bus in the power network so the weak bus have to located properly and also proper location of PMU is to be identified to make the system observable.

In 2020 Abdelazeon A. Abedelsalam proposed FPA to find the optimal location of PMU in the power network. The aim of the work is to determine the minimum number of PMU and to achieve the full network observability .The results they have given shows that the FPA is capable of solving the OPP problem in normal case, in the case of loss of PMU and in the case of line failure \& improve the system reliability \& it gives complete observability of the power network during loss of PMU. FPA also has ability to found PMU location set for same number of PMU and help in increasing the measurement redundancy. The result is compared with other methods also and the result shows that FPA has high performance \& is more effective in solving the OPP problem and finding minimum PMU number for system observability.

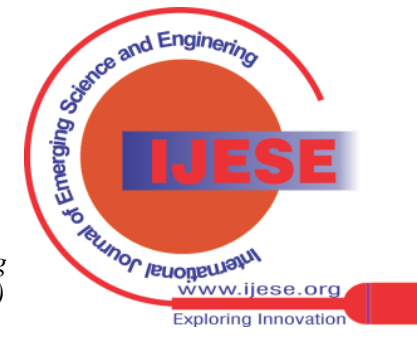




\section{WIDE AREA MEASUREMENT SYSTEM (WAMS)}

Wide Area Measurement system (WAMS) is a group of technologies that can track power system dynamics in real time and discover system flaws that affect system stability. WAMS also assists in the development and implementation of countermeasures. WAMS features superior measurement technology, information technology, and operational structure, allowing it to comprehend and manage the complicated behaviour of huge power networks with ease. It employs global positing system (GPS) signals to synchronise time between PMUs at key nodes in the power network and deliver real-time phasor data to the control centre. The data gives all the dynamic information of power network and helps the operator to do corrective action to improve the reliability and stability of the power network.

\section{A. Goals of WAMS}

1. Monitoring in real time.

2. Analysis of post disturbance.

3. Adjustable protections.

4. Power network restoration.

\section{B. Components}
1. PMU
2. $\mathrm{PDC}$
3. GPS
4. Communicational channel
5. Visualization \& analysis tools.
- Wide area situational awareness system.
- Wide area protection and control.

\section{Needs}

We can avoid major regional blackouts like the ones that occurred in 2003 in North America and Canada. We can take fast action to avert failure if a continuous monitoring application is available.

\section{SYNCHROPHASORS}

Fundamentally synchrophasors are synchronised numbers of times. Synchrophasor refers to the magnitude and phase angle of a sinusoidal wave found in electricity.

\section{A. Phasor}

A sinusoidal wave is defined by its amplitude, frequency, and phase angle, as well as a complex number. Phasors can be used to describe the magnitude and phase angle of the current at a specific point across the transmission line. PMU, like a phasor, measures voltage, current, and frequency at a transmission line point. PMU uses synchrophasor GPS signals to add a time stamp to each phasor data point. When time s023.tamps are added to phasor data, data from several PMUs gets synced and time aligned. Synchrophazor provides a precise representation of the system's regional interconnectedness.

PMU can gather data at a pace of 30 observations per second, unlike SCADA, which collects data every 2-4 seconds. As a result, PMU and synchrophasor always provide a more precise and high resolution image of the grid operator's interconnection and assist in various ways in grid operation. Figure 1. Shows the phasor diagram of the sinusoidal wave. The sine wave depicts how the variable's amplitude fluctuates over time.

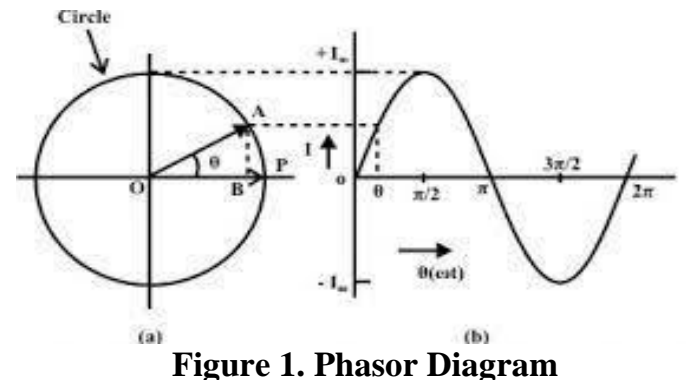

\section{PHASOR MEASUREMENT UNIT (PMU)}

PMU is a device that detects voltage, current, and frequency in an electrical grid using time sources for synchronisation. Because of this feature of the PMU, measuring time synchronised real-time measurement data from any place on the grid becomes very simple. Synchrophasor is the term for this type of measurement.

\section{A. Components of PMU}

1) GPS receiver: With a time beacon, the GPS provides 1pulse/sec information. The most significant aspect of time labelling is that it keeps track of the second, minute, day, and year.

2) Microprocessor: The phasors are controlled by a microprocessor using a recursive algorithm. It can identify the sample numbers at the very first stage by taking into account the information received from the GPS timing massage.

3) Phase-locked oscillator: It is necessary to split the 1 pps in number of pulses/second in order to sample the acquired signal. $30-48 \mathrm{cycle} / \mathrm{sec}$ is the sample rate of the tag.

4) Surge Filtering: With the help of these filters, the same attenuation and phase change of the outlet of the secondary of the current and voltage transformers can be performed. The standard PMUs connectivity into a system is shown in Figure 2. To collect measured signal, phasor data concentrators (PDC) are used. PMUs sent data from various locations. The PDC collects information. The phasor measurements are classified, whereas the signal is not.PMU data is transformed into useful information by a processor. which can be seen on the state of the Human Machine Interface (HMI)

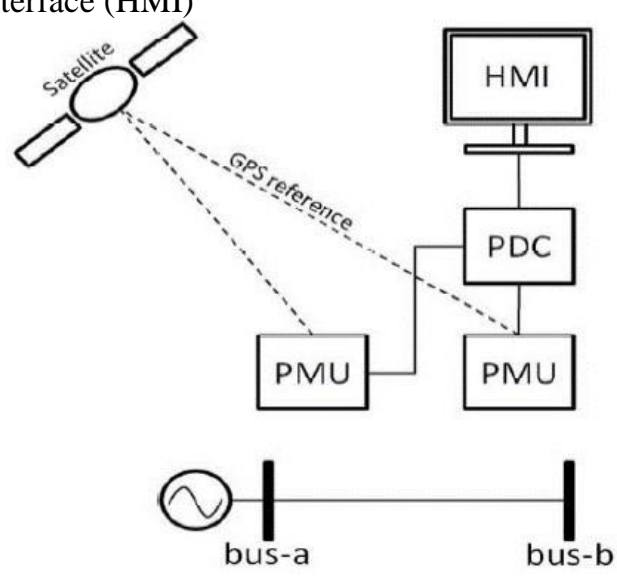

Figure2. Outline of PMU for GPS reference system

Published By:

Blue Eyes Intelligence Engineering and Sciences Publication (BEIESP)

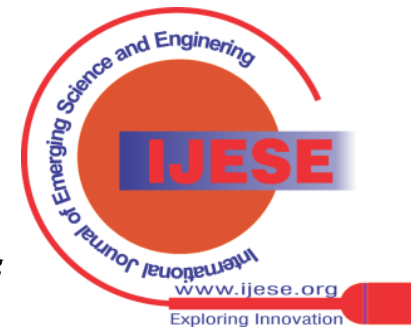




\section{Optimization of Phasor Measurement Unit (PMU) Placement: A Review}

\section{PROBLEM FORMULATION}

PMU placement is treated as a zero-one problem, meaning that if the variable on a bus is one, the PMU is installed in that bus; otherwise, it is not. The placement of the fewest possible PMUs to make the entire system visible is referred to as optimal PMU placement. When a PMU is installed in a bus, surrounding buses become visible as well.

\section{A. Base Case}

The main objective of the optimal PMU placement (OPP) problem is to find minimal set of PMUs in such a way that each bus must be observed by at least one PMU . In normal operating condition, for a D-bus system, OPP problem can be formulated as:

$$
\min \sum_{i=1}^{D} N_{P_{i}}
$$

$$
\text { subject to } A \cdot f(x) \geq b
$$

where D shows the number of buses in the system. Npi shows the number of PMUs to be placed for observability of the system. ' $x$ ' is a binary decision variable whose entries are:

$$
x_{i}=\left\{\begin{array}{l}
1, \text { if a PMU is placed at bus } i \\
0, \text { otherwise }
\end{array}\right.
$$

Under base case , ' $b$ ' is an identity matrix whose elements are 1. In this each bus is observed by at least one PMU. The matrix $\mathrm{b}$ is represented as:

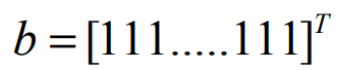

' $A$ ' is a binary connectivity matrix, which is obtained from bus admittance matrix. The entries of matrix ' $A$ ' are :

$$
A_{i, j}=\left\{\begin{array}{l}
1, \text { if } i=j . \\
1, \text { if bus } i \text { and } j \text { are connected } \\
0, \text { otherwise. }
\end{array}\right.
$$

\section{PLACMENT OF PMU USING HEURISTIC METHODS}

\begin{tabular}{|c|c|c|c|}
\hline & Methods Name & Description & Benefits \\
\hline 1 & $\begin{array}{l}\text { Genetic Algorithm } \\
\text { (GA) }\end{array}$ & $\begin{array}{l}\text { It always gives full observability of the power network, minimum } \\
\text { number of PMU placement unit. It takes the connection between the } \\
\text { PMU unit phasors of current. }\end{array}$ & $\begin{array}{l}\text { It gives the Pareto-optimal } \\
\text { solution instead of giving } \\
\text { single solution. }\end{array}$ \\
\hline 2 & Simulated Annealing (SA) & $\begin{array}{l}\text { Genetic probabilistic metaheuristic method. Main aim to find the } \\
\text { approximately reasonable solution in a fixed time regardless of the } \\
\text { best solution. Here for calculating the parameter sensitivity of bas } \\
\text { sensitive analysis method is used. For placement of PMU for } \\
\text { observability in the system incidence metrix method is used. }\end{array}$ & $\begin{array}{l}\text { This method gives Dynamic } \\
\text { data measurement of the } \\
\text { power network and also gives } \\
\text { full observability of the } \\
\text { network. }\end{array}$ \\
\hline 3 & $\begin{array}{l}\text { Particle Swarm } \\
\text { Optimization }\end{array}$ & It is a population based stochastic optimization technique & $\begin{array}{l}\text { It gives of one solution in place } \\
\text { of multiple solution }\end{array}$ \\
\hline 4 & Tabu Search(TS) & $\begin{array}{l}\text { Combination optimization problems are solved by this method. } \\
\text { Incidence matrix of TS, manipulate Tabu Search algorithm and } \\
\text { integer numbers. }\end{array}$ & $\begin{array}{l}\text { It gives accurate results with } \\
\text { fast computational time. }\end{array}$ \\
\hline 5 & $\begin{array}{l}\text { Artificial Neural Network } \\
\text { (ANN) }\end{array}$ & $\begin{array}{l}\text { Here relationship among parameters of the system \& voltage } \\
\text { stability indices, can be made by this algorithm. }\end{array}$ & $\begin{array}{l}\text { It gives many solutions, which } \\
\text { are taken through } \\
\text { computational model. }\end{array}$ \\
\hline 6 & Immune Genetic Algorithm & $\begin{array}{l}\text { IGA relies on the principle of genetic algorithm and also has a } \\
\text { protection mechanism against living organisms such as bacteria and } \\
\text { virus protection. }\end{array}$ & $\begin{array}{l}\text { The speed of the process can be } \\
\text { important easy to apply on a } \\
\text { broad scale device. }\end{array}$ \\
\hline 7 & Differential Evaluation & $\begin{array}{l}\text { It is a metaheuristic Process. Here, by optimising a problem in an } \\
\text { iterative manner, it can develop a candidate solution using both } \\
\text { integrated differential evolution and Pareto Non- dominated Sorting } \\
\text { method. }\end{array}$ & $\begin{array}{l}\text { It has Easy and quick finding } \\
\text { of the number of } \\
\text { Pareto-optimal solutions } \\
\text {, which gives full obsrevability } \\
\text { of the system }\end{array}$ \\
\hline 8 & Matrix Reduction & $\begin{array}{l}\text { Preprocessing method is used to minimize the number of PMUs } \\
\text {.Mathematical methods such as Virtual data elimination } \\
\text { preprocessing, matrix reduction algorithmor Lagrangian relaxation } \\
\text { are used to solve the OPP problem . }\end{array}$ & $\begin{array}{l}\text { Calculation time is decreased } \\
\text { and it is easy to apply in large } \\
\text { scale power network for ob- } \\
\text { servability of network. }\end{array}$ \\
\hline 9 & Mutual Information & $\begin{array}{l}\text { Uncertainty modeling theoretic concept like Mutual information, } \\
\text { are used to minimize the number of PMU. }\end{array}$ & $\begin{array}{l}\text { System uncertainty can be } \\
\text { checked Easily by this method. }\end{array}$ \\
\hline 10 & Ant Colony Optimization & $\begin{array}{l}\text { It's a probabilistic technique. It uses charts that reduce } \\
\text { computational issues. }\end{array}$ & Decrease calculating issues. \\
\hline 11 & Iterated local search & It is a combination of page ranking algorithms.. & $\begin{array}{l}\text { It is easy to understand and put } \\
\text { into practice. }\end{array}$ \\
\hline 12 & Exhaustive Search(ES) & $\begin{array}{l}\text { The method is known as comprehensive because method has } \\
\text { provided a guarantee to provide all accessible before dismissal in } \\
\text { the event of a failure of the unit. }\end{array}$ & $\begin{array}{l}\text { The failure of the system can be } \\
\text { easily noticed. }\end{array}$ \\
\hline
\end{tabular}

There are various heuristic approaches available right now. In a tabular format, a brief summary of numerous heuristic strategies is provided in Table 1

\section{Table- I: Summary of numerous heuristic methods}

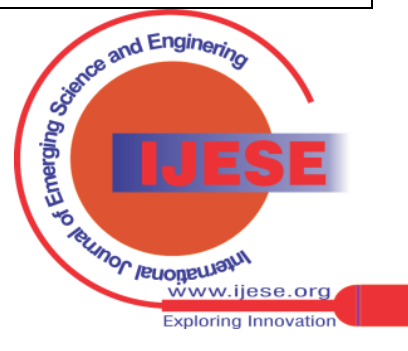




\section{CONCLUSION}

Synchrophasor technology can improve the ability to operate the grid in real time and respond quickly to disturbances. The phasor of system and data can aid the researcher in improving their correctness. The best PMU placement can reduce the number of PMUs in the system while also lowering the system's cost. The system's observability and reliability improve when PMU is used. There are a variety of strategies that can be used to help locate the best site for the PMU. This paper's analysis of PMU and various optimization approaches aids in optimal PMU placement and also aids in the discovery of future optimization techniques.

\section{REFERENCES}

1. D. J. Gaushell, H. T. Darlington, "Supervisory control and data acquisition", Proc. IEEE, vol. 75, no. 12, pp. 1645-1658, 1987.

2. Sha J. (eds) Communications and Information Processing. Communications in Computer and Information Science, vol 288. Springer, Berlin, Heidelberg.

3. EPRI Final Report (1997), Assessment of Applications and Benefits of Phasor Measurement Technology in Power Systems, GE Power Syst. Engineering.

4. S. S. Noureen et al. "Phasor measurement unit integration: A review on optimal PMU placement methods in power system," 2017 IEEE Region 10 Humanitarian Technology Conference (R10-HTC), Dhaka, 2017, pp. 328-332, doi: 10.1109/R10-HTC.2017.8288967.

5. S. Chatterjee et al. "Optimal Placement of PMU Considering Practical Costs in Wide Area Network," 2017 14th IEEE India Council International Conference (INDICON), Roorkee, 2017, pp. 1-6, doi: 10.1109/INDICON.2017.8487742.

6. D. R. Shrivastava, S. A. Siddiqui and K. Verma, "Optimal PMU Placement for Complete Power System Observability under (P-1) Contingency," 2017 IEEE International WIE Conference on Electrical and Computer Engineering (WIECON-ECE), Dehradun, 2017, pp. 129-132, doi: 10.1109/WIECON-ECE.2017.8468924.

7. D. R. Shrivastava, S. A. Siddiqui and K. Verma, "Optimal PMU placement for coordinated observability of power system under contingencies," IEEE International Conference on Circuits and Systems (ICCS), Thiruvananthapuram, 2017, pp. 334-339.

8. M. Jamei et al., "Phasor Measurement Units Optimal Placement and Performance Limits for Fault Localization," in IEEE Journal on Selected Areas in Communications, vol. 38, no. 1, pp. 180-192, Jan. 2020, doi: 10.1109/JSAC.2019.2951971.

9. N. V. Phanendra Babu and P. Suresh Babu, "Optimal Identification and selection of PMU A Methodology," 2019 8th International Conference on Power Systems (ICPS), Jaipur, India, 2019, pp. 1-4, doi: 10.1109/ICPS48983.2019.9067654.

10. N. M. Manousakis and G. N. Korres, "Optimal Allocation of PMU Considering Various Contingencies and Measurement Redundancy," in IEEE Transactions on Instrumentation and Measurement, vol. 69, no. 6, pp. 3403-3411, June 2020, doi: 10.1109/TIM.2019.2932208.

M. Abdelkader, A. Selim, S. Kamel and F. Jurado, "Optimal Placement of PMU for State Estimation of Electrical Power System," 2019 21st International Middle East Power Systems Conference (MEPCON), Cairo, Egypt, 2019, pp. 1048-1052.

11. M. K. Paramathma and D. Devaraj, "Genetic Algorithm Based Approach for the Determination of Optimal Locations and Observability of Phasor Measurement Unit (PMU) Under Smart Grid Environment," 2019 IEEE International Conference on Clean Energy and Energy Efficient Electronics Circuit for Sustainable Development (INCCES), Krishnankoil, India, 2019, pp. 1-4.

12. A. G. Phadke, "Synchronized phasor measurements and their applications", springer science + business media, pp. 1-28, 2008. [2] R. F. Nuqui and A. G. Phadke, "Phasor measurement unit placemen techniques for complete and incomplete observability", IEEE trans. on power delivery, vol. 20, no. 4, pp. 2381-2388, October, 2008.

13. Almutairi, A. M., \& Milanovic, J. V. (2009). Comparison of different methods for optimal placement of PMUs. Bucharest: IEEE Bucharest PowerTech.

14. Devesh Dua, Sanjay Dambhare, et al "Optimal Multistage Scheduling of PMU Placement: An ILP Approach,” IEEE Trans. Power Delivery, vol. 23, no. 4, pp. 1812- 1820, Oct. 2008

15. Arun G. Phadke, "Synchronized Phasor Measurements in Power Systems”, IEEE Computer Applications in Power, vol. 6, no. 2, pp. 10 15, 1993
16. A. Exposito and A. Abur, "Generalized Observability analysis and measurement classification", IEEE Transactions on Power Systems, vol. 13, no. 3, pp. 1090-1095, Aug. 1998.

\section{AUTHORS PROFILE}

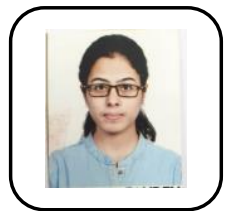

Rachana Pandey Research scholar in Power Systems and Control in Department of Electrica Engineering of SGSITS, Indore. Her area of Interest is Power Systems, Optimization, Power Generation \& Transmission and ANN.

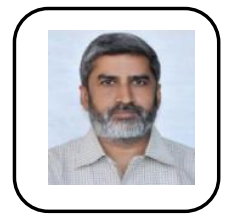

Dr. Harish Kumar Verma.is a professor and head of the Department of Electrical Engineering. He has done his M.E from DAVV Indore .He has completed Ph.D. in Power System under Elctrical Engineering department from SGSITS, Indore [M.P]. He has presented and published various research papers in National and International Journals and Conferences. He is a member of ISTE and IE (India). His area of interest includes Image Processing, Speech Processing, Power System optimisations, ANN, Fuzzy logic and Electrical Drives.

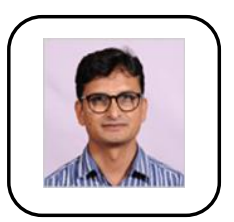

Dr. Arun Parakh has done his ME. from Computer Science Dept. SGSITS in 2003 and Ph.D in Computer Science and Engg from I.I.T Delhi in 2016. . He has presented and published various research papers in National and International Journals and Conferences. His area of interest includes digital systems design, electronic design automation and embedded systems. He is member of board of study at RGPV, Bhopal

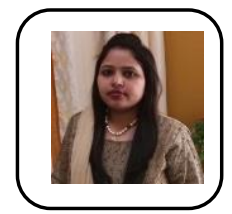

Dr. Cheshta Jain Khare has done her M.E. in powe electronics from SGSITS Indore (M.P). PhD in powe sysyem from SGSITS Indore (M.P). Her research interest Reliability engineering, Hybrid renewable energy system, Power system, Smart grid, Data science. She has presented and published various and Conferences
Published By:

Blue Eyes Intelligence Engineering

and Sciences Publication (BEIESP)

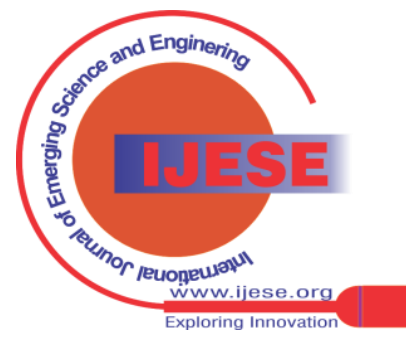

